\title{
Improving operation efficiency of transportation vehicles equipped with a flexible tractive element under conditions of mining enterprises
}

\author{
Mykola Lubenets $^{1}$, Yevhenii Koroviaka ${ }^{1 *}$, Valerii Rastsvietaiev $^{1}$, and Tetiana Lubenets $^{1}$ \\ ${ }^{1}$ Dnipro University of Technology, Department of Transport Systems and Technologies, \\ 19 Yavornytskoho Ave., 49005 Dnipro, Ukraine
}

\begin{abstract}
Usually, basic traffic flows of mining enterprises are effected with the help of transportation vehicles with a flexible tractive element, i.e. belt conveyor, ground ropeway etc. Parameters of transport and operation procedures depend upon mining and geological conditions of mineral mining, technical characteristics, and operation parameters of the transportation vehicles. Objective is to substantiate a new equation of friction of flexible bodies which corresponds to classical concepts of friction of bodies. The methods are based upon the adjustment of common idea of friction of bodies; factors, working upon friction; and solutions of Euler problem on flexible body slip along the fixed block. As a result, common factors of friction of inflexible bodies, i.e. friction force and normal reaction between linearly connected bodies, have been determined; new equation of friction of flexible bodies has been substantiated. Scientific novelty has been represented by means of a new equation of friction of flexible bodies (in the indirect form) which: involves friction force and normal reaction between linearly connected bodies; corresponds to equilibrium conditions of a mechanical system; and coincides with friction law of Coulomb bodies being common one. Practical implication is in the proposed new scientific knowledge giving corrected idea of friction of flexible bodies. The knowledge improves both education level and research level stipulating technological expansion as well as upgrade of transportation vehicles with flexible body. The findings can be applied to improve both efficiency and safety of transportation vehicles with a flexible tractive element under complicated operation conditions; among other things, it concerns mining enterprises.
\end{abstract}

\section{Introduction}

Currently, discontinuous transport plants with autonomous motors [1-8] as well as stationary transportation vehicles with flexible tractive elements (flexible body), for instance, belt conveyors or ground ropeways [9-12], are widely used at mining enterprises for transportation of general goods and auxiliary goods.

\footnotetext{
*Corresponding author: koroviakaye@gmail.com
} 
Tractive ability of a machine with a flexible body (i.e. conveyor belt or rope), pulled on a station blocks, is implemented by means of drive friction at the expense of pressure under the effect of tension.

To compare with belt conveyors where load is distributed along one of the flexible body branches, load of ground ropeways (for instance, in the form of a train of rail transport vessels) is concentrated with point connection to one of the branches. Despite such a difference, there is no fundamental contrast between the mentioned machines.

Design of the machines and their efficient operations involve calculation and are followed by it.

However, available calculation procedures for such facilities are not reliable. Technical specifications and prognosticated operation schedules are in doubt since practices do not support them. Forecast of the key component (i.e. flexible body tension), effecting partially their tractive ability, differs greatly from actual achieving 30\% and more. The machine tractive force is calculated according to a condition of flexible body-drive block coupling corresponding to the current law (equation) of Euler problem on flexible body friction which cannot confirm with the accumulated practices as well as with erroneous ideas of tension distribution within the closed tense flexible body in the context of load transportation [9-12].

The fact speaks for the bias of the calculated parameters of machines with flexible body which affect adversely their efficient use in the national economy.

Hence, correctness of the available calculation procedures, concerning machines with flexible body, comes into question stipulating search for objective computational criteria.

\section{Method of examination}

Academic discussion concerning objective criteria to calculate tractive ability of machines with flexible body (for instance, belt conveyor or ground ropeway), followed by the search for the improved solution of classic Euler problem of flexible body slip along the fixed block, has lasted for two centuries [9].

Consider analytical model of the classic Euler problem (Fig. 1).

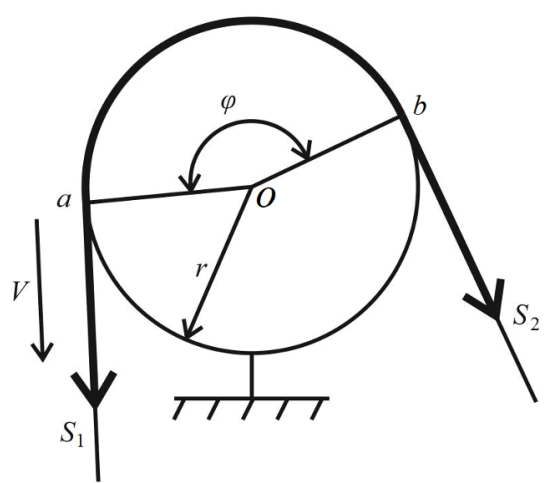

Fig. 1. Analytical model of the classic Euler problem: $S_{1}$ and $S_{2}$ are greater and smaller traction forces of flexible body tension, applied to the flexible body ends; $r$ is radius of a block; $\varphi$ is angle of a block wrap by a flexible body.

In accordance with Euler's conclusion, an ideal thread, wrapping fixed block, is slipping along the fixed block towards greater force exceeding another force by a value of total friction force arising between the thread and the fixed block under the effect of $S_{1}$ and $S_{2}$ forces. Greater force-smaller force ratio is described using the equation: 


$$
\frac{S_{1}}{S_{2}}=e^{f \cdot \varphi}
$$

where $f$ is slipping friction flexible body-block coefficient; and $\varphi$ is an angle of a block wrap by flexible body.

Hence, the friction force, arising during flexible body along the block, is determined by the expression:

$$
F=S_{1}-S_{2}=S_{2} \cdot e^{f \cdot \varphi}-S_{2}=S_{2} \cdot\left(e^{f \cdot \varphi}-1\right)=S_{1} \cdot \frac{\left(e^{f \cdot \varphi}-1\right)}{e^{f \cdot \varphi}},
$$

where $F$ is friction force in the process of a flexible body slipping along the block.

Thus, tractive force of a machine during flexible body-block coupling is forecasted ample of minimum traction force of one of the branches of the flexible body on the block contact while slipping:

$$
S_{1 \min }=\frac{F_{0} k_{T}}{\left(e^{\mu \cdot \varphi}-1\right)} ; S_{1 \min }=\frac{F_{0} \cdot k_{T} \cdot e^{f \cdot \varphi}}{\left(e^{\mu \cdot \varphi}-1\right)},
$$

where $S_{1 \min }$, and $S_{2 \min }$ are minimum traction forces of the flexible body on the block contact; $F_{0}$ is implemented traction force of a drive block during its coupling with the flexible body; and $k_{T}$ is safety coefficient of the traction force.

The problem of the improvement of Euler equation of friction of flexible bodies as well corresponding criterion of implementation by a block of the preset traction force was considered by the prominent world researchers inclusive of our countrymen - employees of the Dnipro University of Technology, Dnipro National University, and Institute of Geotechnical Mechanics named by N. Poljakov of National Academy of Sciences of Ukraine. Unfortunately, they have not succeeded yet [9, 13].

It has been determined recently that the current laws of natural science in the field of friction of bodies, on which both stationary and self-propelled transportation vehicles are based upon, are not coincide with each other. Among other things, the known Euler equation of friction of flexible bodies, and its refinements, proposed during centuries, cannot meet prevailing ideas of scientists concerning friction [13, 14]. Namely, the listed indirect solutions of classic Euler problem do not involve universally recognized factor of friction of bodies, i.e. normal reaction between bodies, and do not support its linear connection with friction force which is indicative of incompatibility of the current Coulomb and Euler laws of friction of bodies in one of the fields of natural sciences - field of friction of bodies [13 - 15].

Moreover, Euler equation of friction of flexible bodies cannot correspond to the laws of classic mechanics, for instance, equilibrium conditions of mechanical system. According to the current calculation procedures, the calculated response and tractive force on a block (such as for $\varphi$ angle of its wrap by a flexible body being $180^{\circ}$ ) are not equal to force total and force difference applied to the flexible body ends [14].

The carried out analysis of the current calculation procedure, concerning the machine, also supports the idea that together with the use of doubtful Euler equation of friction of flexible bodies, it cannot provide fulfillment of equilibrium conditions of classic mechanics, i.e. real response within a drive station is not equal to analytical one [15 - 18].

Moreover, simplified idea of distribution of a flexible body tensions has rooted in the practice of design of machines.

Forecasting with the help of calculation procedures concerning tension machines within closed pulled on the blocks of tension station and drive station in their flexible body is 
performed like in the open series chain of load elements. Moreover, action of tension station block is not taken into consideration which "balances" evidently tension changes in load branch of a machine, and its idle branch resulting in incorrect evaluation.

According to our expectations, when load is being transported by means of a machine, its flexible body is under complex stress and strain state. It is effected by the following: prestressing force; load weight and own weight; their velocity; transmitted circular traction force of the machine, depending upon its frictional characteristics of a flexible body and a block etc.

In this context, tension distribution within the flexible body, simulated by calculation procedures, should follow the laws of classic mechanics inclusive of balance force conditions and conditions of mechanical system moments, principle of mechanical energy conservation within the closed mechanical system etc.

Hence, integrated studies have been carried out to verify the disadvantages of the current procedure of a machine design and to identify objective design criteria.

To determine real distribution of tensions within closed pulled on blocks flexible body, experiments with the help of test bench (i.e. short stationary machine with flexible body) were carried out while simulating distributed load and concentrated load.

Consider analytical scheme of a machine with a flexible body (Fig. 2).

Fig. 3 demonstrates analytical model of a test bench of a machine with a flexible body to simulate distributed load within its branches.

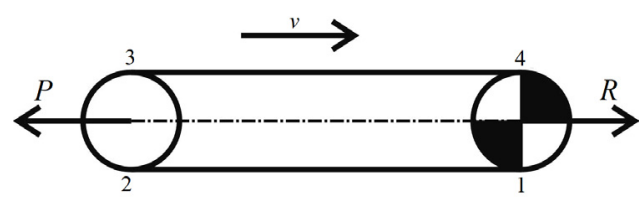

Fig. 2. Kinematic scheme of a machine with a flexible body: $P$ is tension force of a flexible body within traction station; $R$ is response within a drive station towards transportation; $v$ is velocity of the flexible body; $1-4$ - characteristic contacts of the flexible body with blocks of traction station and drive station.

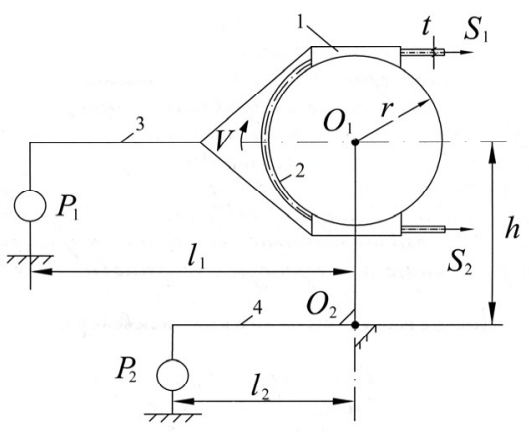

Fig. 3. Analytical model of a test bench while distributed load simulating: 1 - belt brake; $2-$ block of traction station; 3 and 4 - levers; $S_{2}$ and $S_{1}$ are belt traction on a block; $l_{1}$ and $l_{2}$ are length of the levers; $r$ is block radius; $h$ is distance between hinges; $P_{1}$ and $P_{2}$ are dynamometers.

The test bench is a short horizontal belt conveyor. Block of traction station 2 is mounted on a hinge $O_{1}$ of a lever with rotation axis $O_{2}$. The bench is equipped with belt brake 1 to slowdown a block of traction station 2, simulating traction force of a conveyor or traction force of a load being transported, and dynamometers $P_{1}$, and $P_{2}$, fastened on levers 3 and 4 . They are meant to measure friction force between the conveyor belt and the block, and pretension force of the conveyor belt. Hence, pretension force of the conveyor belt is supported and controlled by an elastic element - dynamometer.

Neither block of the conveyor drive station, nor a tension device of the conveyor belt is shown. Action of traction forces $S_{1}$ and $S_{2}$ substitutes the conveyor part in the analytical model of the test bench.

Idea of the test is to balance a moment of traction force $S_{I}$ and $S_{2}$ of the conveyor belt and force moment of friction $F$ of a conveyor belt on tension block of the belt conveyor 
during their friction simulating traction force, implementing by it, and traction force of the distributed load being transported. In terms of the preset force moment of friction force $\mathrm{F}$ of the conveyor belt on the tension block of the conveyor, indications of dynamometers $P_{1}$ and $P_{2}$ are recorded. The tests were carried out under the preset pretension of conveyor belt $P$ being equal to $P_{2} l_{2} / l_{2}$.

Qualitative tension changes on the drive station block in the process of different traction forces implementation on it was determined with the help of theoretical mechanics methods. Within the areas of conveyor belt creeping on the block 2 and running-out from it, traction forces $S_{2}$ and $S_{1}$ are roots of two linear equations of moment balance of the mechanical system:

$$
\left\{\begin{array}{l}
\sum_{i=1}^{n} M_{O_{1}}=S_{1} \cdot r-S_{2} \cdot r-P_{1} \cdot l_{1}=0 \\
\sum_{i=1}^{k} M_{O_{2}}=S_{1} \cdot(h+r)+S_{2}(h-r)-P_{2} \cdot l_{2}-P_{1} \cdot l_{1}=0,
\end{array}\right.
$$

where $\sum_{i=1}^{n} M_{O_{1}}$ is a total of force moments of the mechanical system as to $O_{1}$ hinge; $\sum_{i=1}^{n} M_{O_{2}}$ is a total of force moments of the mechanical system as to $O_{2}$ hinge; $S_{1}$ is tension within a flexible body branch running-out from the block; $S_{2}$ is tension within a flexible body branch running-on the block; $l_{1}$ and $l_{2}$ are lengths of levers; $P_{1}$ and $P_{2}$ are indications of dynamometers; $r$ is the block radius; and $h$ is distance between hinges.

Traction forces $S_{1}$ and $S_{2}$ are determined using the expressions:

$$
\begin{aligned}
& S_{1}=\frac{P_{2} \cdot l_{2} \cdot r+P_{1} \cdot l_{1} \cdot h}{2 \cdot r \cdot h} ; \\
& S_{2}=\frac{P_{2} \cdot l_{2} \cdot r-P_{1} \cdot l_{1} \cdot h}{2 \cdot r \cdot h} .
\end{aligned}
$$

Visual observations during simulation of the distributed load within the branches of a flexible body of a machine have helped determine following characteristics of its functioning:

- when the machine was operating in the idle $X X$ and in the running modes, indications of $P_{2}$ dynamometer varied moderately during a complete rotation of the closed flexible body (it was not more than $\pm 5 \%$ of the stable value being $74 \mathrm{kgf}$ and associated with determination of joint of the flexible body in drive station and tension station); thus, indication of $P_{1}$ dynamometer was being recorded at the moment of the flexible body joint determination between its stations;

- when the machine was operating in the idle XX mode, the whippings of its load branch and idle branch were almost identical, i.e. $83 \pm 1 \mathrm{~mm}$ (the whippings were measured with the help of a metal ruler in the central part of the conveyor belt branches relative to a thread strained along blocks of the stations, Fig. 4);

- along with step-like increase in a braking moment, whipping of load branch decreased on 2 block axis of the machine and whipping of an idle branch increased which means tension increase and decrease in its corresponding branches; i.e. belt tension within characteristic $1^{\text {st, }} 2^{\text {nd }}, 3^{\text {rd }}$, and $4^{\text {th }}$ points of its contacts with blocks of tension station and drive station;

- in the process of the flexible body slip along block 2 of the machine, whipping of its load branch dropped down its minimum (i.e. $42 \pm 1 \mathrm{~mm}$ ); by contrast, whipping of its idle branch increased up to maximum (i.e. $129 \pm 1 \mathrm{~mm}$ ). 
$G$ load was applied during simulation of the concentrated load instead of a belt brake which was not used at the test bench of the machine (Fig. 3). The load, held with the help of $F$ dynamometer, balanced on the tension station block with conveyor belt (Fig. 4 represents kinematic scheme to implement the concentrated force on the flexible body of the machine).

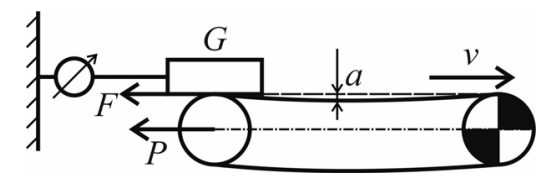

Fig. 4. Kinematic scheme to implement the concentrated force on the flexible body of the machine: $P$ is a force of the flexible body pretension; $G$ is load; $F$ is dynamometer and friction force between the load and flexible body; $v$ is velocity of the flexible body; $a$ is branch whipping of the machine flexible body.

Methods of theoretical mechanics were applied to determine quantitative tension change in the flexible body on the machine drive station in the process of various traction powers implementation on it. Within areas of conveyor belt creeping on block 2 and running-out from it, traction forces $S_{2}$ and $S_{1}$ are roots of two linear equations of moment balance and mechanical system forces:

$$
\left\{\begin{array}{l}
\sum_{i=1}^{n} M_{O_{1}}=S_{1} \cdot r-S_{2} \cdot r-F \cdot r=0 \\
\sum_{i=1}^{k} F_{i}=S_{1}+S_{2}-\frac{P_{2} \cdot l_{2}}{h}=0
\end{array}\right.
$$

where $\sum_{i=1}^{n} M_{O_{1}}$ is total of the mechanical system moments relative to hinge $O_{1} ; \sum_{i=1}^{n} F_{i}$ is total of forces of the machine flexible body tension.

In this context, traction forces $S_{1}$ and $S_{2}$ are determined using the expressions:

$$
\begin{aligned}
& S_{1}=\frac{P_{2} \cdot l_{2}}{2 \cdot h}+\frac{F}{2} ; \\
& S_{2}=\frac{P_{2} \cdot l_{2}}{2 \cdot h}-\frac{F}{2} .
\end{aligned}
$$

\section{Results and discussion}

While modeling concentrated load on the machine flexible body, visual observations have helped determine similar observations:

- when the machine was operating in the idle $X X$ and in the running modes, indications of $P_{2}$ dynamometer varied moderately during a complete rotation of the closed flexible body (it was not more than $\pm 5 \%$ of the stable value being $74 \mathrm{kgf}$ );

- when the machine was operating in the idle $X X$ mode, the whippings of its load branch and idle branch were almost identical; and

- when body was originating friction on the flexible body of the concentrated friction force $F$ in the neighbourhood of tension block 2, whipping of its load branch decreased and whipping of its idle branch increased conversely.

Following Table 1 demonstrates test results while simulating distributed load and concentrated load. 
Table 1. Experimental results concerning simulation of distributed load and concentrated load.

\begin{tabular}{|c|c|c|c|c|c|c|}
\hline \multirow{2}{*}{ No. } & \multicolumn{4}{|c|}{ Test conditions } & \multicolumn{2}{c|}{ Branch tension } \\
\cline { 2 - 7 } & $\begin{array}{c}\text { Friction mode } \\
\text { of a belt }\end{array}$ & $\begin{array}{c}\text { Belt } \\
\text { condition }\end{array}$ & $P_{1} / F, \mathrm{kgf}$ & $P_{2}, \mathrm{kgf}$ & $S_{1}=F_{4}, \mathrm{kgf}$ & $S_{2}=F_{1}, \mathrm{kgf}$ \\
\hline 1 & & & $0 /-$ & 74 & 143.4 & 143.4 \\
2 & & & $7.6 /-$ & 74 & 174.7 & 112.1 \\
3 & \multirow{2}{*}{ coupling } & \multirow{2}{*}{ dry } & $10.5 /-$ & 74 & 186.7 & 100.1 \\
4 & & & $-/ 21$ & 74 & 132.9 & 153.9 \\
5 & & & $-/ 33$ & 74 & 126.9 & 159.9 \\
\hline 6 & \multirow{2}{*}{ coupling } & \multirow{2}{*}{ wet } & $0 /-$ & 74 & 143.4 & 143.4 \\
7 & & $3.3 /-$ & 74 & 147.0 & 129.8 \\
\hline 6 & slipping & dry & $13.3 /-$ & 74 & 198.2 & 88.6 \\
\hline 7 & slipping & wet & $4.2 /-$ & 74 & 160.7 & 126.1 \\
\hline
\end{tabular}

As a whole, the experiments, carried out with the use of a test bench, make it possible to conclude the following:

- in terms of different test modes, reaction $P$ and pretension $P$ of the machine flexible body within drive station and tension station hold constant and equal mutually;

- in terms of different test modes, implementation of various traction powers $F_{0}$ of the machine with the help of flexible body friction on the drive block is performed under constant $R$ response within the drive station;

- in terms of the tests, concerning the flexible body tension on two contacts with the drive station, when different traction powers are transmitted, "mirror" changes take place, i.e. increase is available within creeping on the drive block, and similar decrease is available within running-out point; and

- in terms of various test modes, stretching of the closed pulled flexible body is unaffected giving evidence of its potential energy preservation including total mechanical energy.

Hence, regularities concerning tension distribution within the characteristic points of the closed, previously pulled on blocks, a flexible body have been determined during movement over circular trajectory which is observed in transportation vehicles with a flexible body.

It develops that:

- tension within characteristic points of a flexible body depends upon a value of traction power on a block rather than upon load nature (i.e. distributed or concentrated), and upon its distribution within branches under otherwise equal test conditions (inclusive of its pretension);

- tension distribution of a flexible body characteristic points during its movement corresponds to such fundamentals of classic mechanics as balance conditions of a mechanical system, a law of mechanical energy of a flexible body conservation within the closed mechanical system, Hooke's law etc. rather than to the characteristics being typical for open chain of load elements which is implemented unfortunately by the current procedures of machine design [9-12];

- in terms of the set pretension of a flexible body, its potential energy (inclusive of area limited by the dependence of the flexible body outline tension) to which different traction powers are transmitted, experiences no variations giving evidence of observance of mechanical energy conservation within the closed mechanical system;

- tension change in the machine branches is balanced under the effect of a tension station block.

Thus, averaged tension of a flexible body along its outline varies uniformly by a value of traction power, being implemented, since in this context a law of mechanical energy conservation within the closed mechanical system is observed. Local "step-like" changes in 
a flexible body tension are confined to its contacts with blocks, and application of the concentrated forcers; moreover, they are proportional to relative length of the considered areas of the flexible body between adjacent contacts. Nevertheless, they are not more than tensions within characteristic machine points.

Analysis of the obtained data made it possible to develop theoretical tension model of the closed flexible body within characteristic points of contact with blocks of a drive station and tension station during load transportation which corresponds to our forecasts.

Theoretical model of a conveyor belt tension is equation system of tensioning balance of a flexible body corresponding to the fundamentals of force balance and balance of mechanical system balance as well as to a law of conservation of mechanical energy of a flexible body within the closed mechanical system:

$$
\left\{\begin{array}{l}
M_{0}=F_{0} \cdot d=F_{n-s} \cdot d \Rightarrow F_{0}=F_{n-s} \\
F_{n-s}=F_{4}-F_{1} \\
R=F_{1}+F_{4} \\
F_{2-3}=F_{3}-F_{2} \\
P=F_{2}+F_{3} \\
P+\left(q+2 \cdot q_{0}\right) \cdot l \cdot g \cdot \sin \gamma+F=N_{x} \\
F_{n-s}=F_{1-2}+F_{2-3}+F_{3-4}
\end{array}\right.
$$

where $M_{0}$ is external rotational moment, $\mathrm{N} \cdot \mathrm{m} ; F_{0}$ is external circular traction force, $\mathrm{N} ; d$ is block diameter, $\mathrm{m} ; F_{n-s}$ is circular traction force of a conveyor, implemented by friction, $\mathrm{N}$; $F_{1-2}$ is traction force of section 1-2 of a belt conveyor, $\mathrm{N} ; F_{2-3}$ is traction force of section 2-3 of a belt conveyor, $\mathrm{N} ; F_{3-4}$ is traction force of section 3-4 of a belt conveyor, $\mathrm{N} ; R$ is response on the drive station towards transportation, $\mathrm{N} ; P$ is tension force of the conveyor belt within tension station, $\mathrm{N} ; q$ is linear mass of the load, $\mathrm{kg} / \mathrm{m} ; q_{0}$ is linear mass of the conveyor belt, $\mathrm{kg} / \mathrm{m} ; g$ is gravitation acceleration, $\mathrm{m} / \mathrm{s}^{2} ; \gamma$ is angle of the conveyor slope, $\mathrm{rad} ; l$ is length of the conveyor, $\mathrm{m} ; F$ is concentrated force applied to the flexible body.

To determine correct equation of friction of flexible bodies, in the context of conservative mechanical system we propose a new theoretical conclusion concerning the results of classic Euler problem solution on the slipping of a flexible body along a stationary block corresponding to the laws of classic mechanics for the first time ever $[13,15-18]$.

The conclusion has been made owing to the introduction of a new Coulomb body friction law (instead of obsolete Amonton law of body friction) into a system of differential equations of balance of forces and moments during flexible body along the block proposed by Euler. The new equation corresponds to the revised law of mechanical energy conservation within the closed mechanical system, and, consequently, its following solution $[13-15]$ :

$$
\left\{\begin{array}{l}
d N=\left(S-q \cdot v^{2}\right) \cdot d a \\
r \cdot d S=r \cdot d F \\
d F=\frac{F_{C}}{\varphi} \cdot d a+C \cdot d N \\
\frac{\partial N}{\partial f}=\frac{\partial\left(\int_{0} S \cdot d a\right)}{\partial f}=0
\end{array}\right.
$$


where $d N$ is normal surface element of a flexible body-block reaction; $S$ is the flexible body tension within the set section; $d a$ is common wrapping angle corresponding to a the surface element of the flexible body which length is $d l ; d F$ is friction force between the flexible body surface element and the block; $\alpha$ is angle of the set section of the flexible body contacting with the block; $\varphi$ is angle of the block wrapping by the flexible body; $r$ is the block radius; $F_{C}$ and $C$ is friction parameters of Coulomb bodies.

[13] is solution for the mentioned balance equation system:

$$
S_{1}-S_{2}=f \cdot\left(\varphi \cdot \frac{S_{1}+S_{2}-2 \cdot q \cdot v^{2}}{2}\right),
$$

where $f$ is coefficient of friction between a flexible body and a block.

To compare with Euler equation of friction of flexible bodies, the derived equation corresponds to ideas of philosophers and scientists of flexible body friction which has been formulated during centuries, and laws of classic mechanics: conditions of force and moment balance of mechanical system as well as a law of mechanical energy conservation within the closed mechanical system [15].

Indirectly, the new equation of friction of flexible bodies involves universally acknowledged "normal response" and "friction force" being interconnected linearly with the help of "friction coefficient" which corresponds to the known ideas of friction, determined during centuries, and coincides with dominating Coulomb law of friction of bodies [14]:

$$
F=\left(S_{1}-S_{2}\right)=f \cdot\left(\varphi \cdot \frac{S_{1}+S_{2}-2 \cdot q \cdot v^{2}}{2}\right)=f \cdot N,
$$

where $F$ is friction force, $\mathrm{N} ; N$ is normal response between bodies, $\mathrm{N}$.

The abovementioned speaks for overcoming of the available incompatibility of the current laws of body friction by Coulomb and Euler in one of the fields of natural sciences by means of new theoretical equation (law) of flexible body friction which responds with classic mechanics law for the first time ever.

Hence, to implement the set traction power in the context of the new criterion condition of a flexible body coupling with a block - machine should provide sufficient normal response $N$ between bodies like in the case of friction of inflexible bodies which corresponds to body friction Coulomb law as well as the universally recognized friction ideas:

$$
N=\frac{\varphi \cdot\left(S_{1}+S_{2}-2 q v^{2}\right)}{2} \geq \frac{F_{0}}{f},
$$

where $F_{0}$ is circular traction power;

or

$$
\left(S_{1}+S_{2}\right)=\frac{2 N}{\varphi}+2 q v^{2}, N \geq \frac{F_{0}}{f} .
$$

Fig. 5 demonstrates diagrams of tension of a flexible body of horizontal belt conveyor when drive station is located within head of a machine and within its back; the diagrams were plotted in accordance with the analytical model, derived above, and the current technique of machine design. 


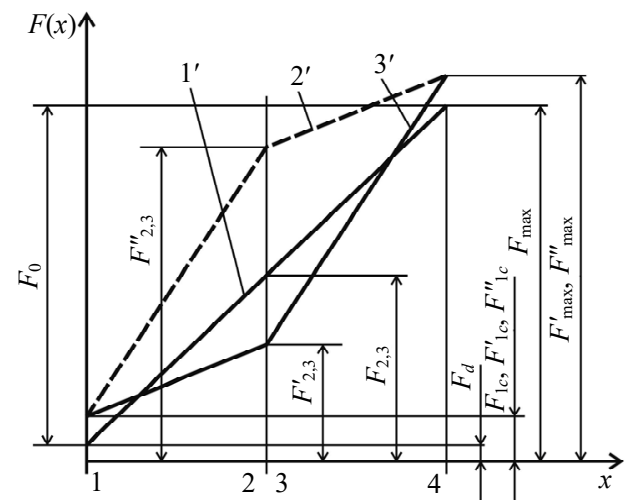

Fig 5. Tension diagrams $F(x)$ of a flexible body of a belt conveyor with flexible body from its section $x$ : $1^{\prime}$ - those, plotted in accordance with analytical model when drive station is located within head of a machine and within its back; $2^{\prime}-$ those, plotted in accordance with the available machine calculation procedure when drive station is located within back of the machine; $3^{\prime}$ - those, plotted in accordance with the available machine calculation procedure when drive station is located within a head of the machine; $F_{2,3}$ is flexible body tension within characteristic points 2 and $3 ; F_{1 c}$ is minimum flexible body tension in terms of coupling; $F_{d}$ is minimum flexible body tension in terms of deflection; $F_{\max }$ is maximum tension of the flexible body.

It follows from the diagram that relative errors of forecast, using the current calculation techniques for pretension and maximum tension of a flexible body for the set horizontal belt conveyor when drive station is located within head of a machine and within its back, are from $-30 \%$ to $+55 \%$ which is indicative of uncertainty of the calculation criteria being applied.

\section{Conclusions}

Thus, analytical model to distribute tensions of the closed pulled flexible body during load transportation has been developed. The model corresponds to balance fundamentals of classic mechanics and to a law of mechanical energy conservation within the closed mechanical system.

A new equation of friction of flexible bodies has been derived; for the first time, the equation is in keeping with scientific concepts concerning body friction, and corresponds to laws of mechanics: balance conditions of a mechanical system, and a law of mechanical energy conservation within the closed mechanical system.

Objective criteria to design machines with a flexible body have been determined; the criteria are based upon new knowledge concerning flexible body friction along a block, and its tension while load transporting which corresponds to laws of mechanics for the first time ever favouring their improved performance under complex operation conditions of mining enterprises.

The research is carried out at TST Department to substantiate objective calculation criteria for transportation vehicles with flexible body, and to improve teaching of such fundamental and applied subjects as Mechanics, Physics, Mathematics, Structural Resistance, and transporting subjects relying upon determination of objective laws of natural sciences in the field of friction inclusive of friction of flexible bodies. The authors are grateful for the best practices of researchers concerning correction of solution of classic Euler equation on flexible body slipping along stationary block. Moreover, the authors are thankful for founders of TST Department of the Dnipro University of Technology for the design of test transportation devices which helped obtain the required result. 


\section{References}

1. Shirin, A., Rastsvetaev, V., \& Morozova, T. (2012). Estimation of reliability and capacity of auxiliary vehicles while preparing coal reserves for stoping. Geomechanical Processes During Underground Mining - Proceedings of the School of Underground Mining, 105-108. https://doi.org/10.1201/b13157-18

2. Shyrin, L., \& Iniutkin, I. (2018). Substantiating operational parameters of loadhaul-dumpers in the context of irregular-shaped underground mine workings. E3S Web of Conferences, (60), 00036. https://doi.org/10.1051/e3sconf/20186000036

3. Rastsvietaiev, V.O., Posunko, L.M., Shyrin, A.L., \& Zheglov, S.S. (2015). Estimation of factors limiting efficiency of transport schemes while preparing coal reserves in Western Donbas mines. Mining of Mineral Deposits, 9(1), 117-123. https://doi.org/10.15407/mining09.01.117

4. Rastsvietaiev, V.O. (2014). Prospects of transport and technological systems improvement during performing of mounting/dismounting operations in conditions of Western Donbass mines. Mining of Mineral Deposits, 8(2), 143-148. https://doi.org/10.15407/mining08.02.143

5. Bartashevskii, S., Koptovets, O., Novitskii, O., \& Afonin, D. (2014). Perspective ways of mine locomotives autonomy increase. Progressive Technologies of Coal, Coalbed Methane, and Ores Mining, 293-296. https://doi.org/10.1201/b17547-51

6. Gutarevych, V. (2012). A mathematical model study of suspended monorail. Transport Problems: International scientific journal, 7(3), 61-66.

7. Gutarevych, V. (2014). Dynamic model of movement of mine suspended monorail. Transport Problems: International scientific journal, 9(1). 13-18.

8. Gutarevich, V.O. (2015). Longitudinal dynamics of mine suspended monorail. Naukovyi Visnyk Natsionalnoho Hirnychoho Universytetu, (1), 83-88.

9. Andreev, A.V. (1963). Peredacha treniem. Moskva: Mashhiz.

10. Denishchenko, A.V. (2005). About the calculation of static cable tension. Naukovyi Visnyk Natsionalnoho Hirnychoho Universytetu, (8), 64-65.

11. Shirin, L.N., Denishchenko, A.V., Yurchenko, O.O., \& Mikhalev, D.V. (2012). Methodology for determination of rope vehicles energy consumption. Naukovyi Visnyk Natsionalnoho Hirnychoho Universytetu, (4), 64-69.

12. Denyshchenko, O., Shyrin, A., Rastsvietaiev, V., \& Cherniaiev, O. (2018). Forming the Structure of Automated System to Control Ground Heavy-Type Ropeways. Naukovyi Visnyk Natsionalnoho Hirnychoho Universytetu, (4), 79-85. https://doi.org/10.29202/nvngu/2018-4/12

13. Lubenets, N.A. (2014). New solution of the Euler problem about a flexible body sliding over a fixed block. Naukovyi Visnyk Natsionalnoho Hirnychoho Universytetu, (3), 45-53.

14. Lubenets, M. (2017). Friction of flexible friction effect and general law on friction in operation of transport machines with flexible tie body. Mining of Mineral Deposits, 11(4), 104-110. https://doi.org/10.15407/mining11.04.104

15. Lubenets, N. (2017). Conservation of mechanical energy in flexible body friction in block. Collection of research papers of national mining university, (50), 194-203.

16. Koroviaka, Ye. \& Lubenets, T. (2017). Substantiation of the method for constructing the diagram of the horizontal belt conveyor tightness. Mining of Mineral Deposits, 11(3), 111-116. https://doi.org/10.15407/mining11.03.111

17. Korovyaka, E.A., \& Lubenets, T.N. (2015). Substantiation of operational modes for extensible belt conveyers of mining enterprises. Collection of research papers of national mining university, (49), 116-121.

18. Lubenets, N.A., \& Lubenets, T.N. (2012). Effect of centrifugal forces of a flexible body on tractive friction implementation. Naukovyi Visnyk Natsionalnoho Hirnychoho Universytetu, (5), 28-33. 